\title{
Induced Land Use Emissions due to First and Second Generation Biofuels and Uncertainty in Land Use Emission Factors
}

\author{
Farzad Taheripour and Wallace E. Tyner \\ Department of Agricultural Economics, Purdue University, West Lafayette, IN 47907-2056, USA \\ Correspondence should be addressed to Farzad Taheripour; tfarzad@purdue.edu
}

Received 4 December 2012; Revised 20 February 2013; Accepted 7 March 2013

Academic Editor: Amani Elobeid

Copyright (C) 2013 F. Taheripour and W. E. Tyner. This is an open access article distributed under the Creative Commons Attribution License, which permits unrestricted use, distribution, and reproduction in any medium, provided the original work is properly cited.

\begin{abstract}
Much research has estimated induced land use changes (ILUCs) and emissions for first generation biofuels. Relatively little has provided estimates for the second generation biofuels. This paper estimates ILUC emissions for the first and second generation biofuels. Estimated ILUC emissions are uncertain not only because their associated land use changes are uncertain, but also because of uncertainty in the land use emission factors (EFs). This paper also examines uncertainties related to these factors. The results suggest that converting crop residues to biofuel has no significant ILUC emissions, but that is not the case for dedicated energy crops. Use of dedicated energy crops transfers managed natural land and marginal land (cropland-pasture) to crop production. Producing biogasoline from miscanthus generates the lowest land requirement among alterative pathways. The largest land requirement is associated with switchgrass. The difference is due largely to the assumed yields of switchgrass and miscanthus. The three major conclusions from uncertainty in emissions analyses are (1) inclusion or exclusion of cropland-pasture makes a huge difference; (2) changes in soil carbon sequestration due to changes in land cover vegetation play an important role; and (3) there is wide divergence among the emission factor sources, especially for dedicated crop conversion to ethanol.
\end{abstract}

\section{Introduction}

The land use consequences of global biofuel programs and their contributions to GHG emissions have been the focal point of many debates and research studies in recent years. Research studies in this field usually estimate ILUC emissions in two phases. They first estimate ILUCs due to biofuel production using either partial or general equilibrium models. Then they apply land use emission factors (EFs), which measure vegetation and soil carbon fluxes and are obtained from biophysical models, to calculate the ILUC emissions given the estimated ILUCs. Both of these phases are subject to uncertainties. Several papers examined major uncertainties related to the estimates for ILUCs and their geographical distributions. Wicke et al. [1] reviewed major studies in this area and highlighted deficiencies of economic models used to assess the ILUCs due to biofuels and their corresponding uncertainties. However, most of these studies focused on the land use emissions due to first generation biofuels such as corn ethanol, sugarcane ethanol, and biodiesel. Few attempts have been made to estimate these emissions for second generation biofuels which convert cellulosic materials into liquid fuels. In addition, uncertainties related to the EFs and their importance for estimates of the ILUC emissions due to biofuels have received little or no attention to date. This paper examines uncertainties in emission estimates for ILUCs due to first and second generation biofuels.

To accomplish this task we first provide a set of estimates for ILUCs from several biofuel pathways, including both first and second generation biofuels. To model ILUCs for alternative biofuel pathways we used a computable general equilibrium model. The model is built on the GTAP-BIO model which is designed and frequently used to assess ILUCs due to biofuels [2-6]. Since the original GTAP-BIO model only covers the first generation biofuels, several new activities are introduced into this modeling framework and its database to estimate ILUCs for new biofuel pathways which convert cellulosic materials into liquid biofuels. The next section of this paper introduces the main features of the GTAP-BIO model, explains the key configurations of the new industries 
added to the model, and presents estimated ILUCs for several new biofuel pathways. Then we describe the approaches, data sources, and assumptions for four existing major EFs. After that, ILUC emissions for selected biofuel pathways are calculated using these four different emission factors. Finally, uncertainties in EFs and their consequences for the estimated ILUCs for alternative biofuel pathways are examined.

\section{ILUCs due to Selected Biofuel Pathways}

2.1. Background. The GTAP-BIO model is a multiregional computable general equilibrium model which simulates consumer and producer behaviors and traces production, consumption, and trade of goods and services including biofuels and their by-products at a global scale. The GTAPBIO model takes into account resource constraints and links economic and biophysical information through the market for land where agricultural, livestock, and forestry compete for limited land resources.

To evaluate ILUCs due to biofuel production and policy the GTAP-BIO model links biofuel industries with other economic activities and takes into account several lines of market-mediated responses, which are the key determinants of the ILUCs due to biofuel and policy. In particular, the model takes into account (1) substitution among energy items, including fossil fuels and biofuels, and between energy and other inputs in production functions of goods and services; (2) substitution among energy items, including fossil fuel and biofuels, at household level; (3) interactions between food and fuel; (4) substitution among crops and biofuels by-products such as distillers grains and oilseed meals in animal feed rations; (5) competition for cropland among crop producers and shifting cropland to biofuel feedstock crops from other uses; (6) intensification in land use; (7) and conversion of forest and pasture land to cropland (extensification). Golub and Hertel [7] have reviewed the roles of these market-mediated responses in determining ILUCs using the GTAP-BIO model and discussed their key corresponding uncertainties.

2.2. Model Modifications. The original GTAP-BIO model [2, 3 ] and its newer versions [4-6] only cover production and consumption of first generation of biofuels including ethanol produced from grains and sugarcane and biodiesel produced from oilseeds. To evaluate ILUCs for a wider range of biofuel pathways including the second generation of biofuels which convert cellulosic materials into biofuels, we modified the GTAP-BIO model and its database.

The new model is based on version 7 of GTAP database which depicts the world economy in 2004. In addition to first generation biofuels, several new industries are introduced into this database to expand the space of biofuel alternatives to second generation biofuels. In particular, we introduced three feedstock industries (corn stover, miscanthus, and switchgrass) and six advanced biofuel industries (corn stover biogasoline, miscanthus biogasoline, switchgrass biogasoline, corn stover ethanol, miscanthus ethanol, and switchgrass ethanol) into the database. The corn stover industry is an
TABLE 1: Cost structures of corn stover, miscanthus, and switchgrass activities (percentages of total costs).

\begin{tabular}{lccc}
\hline Cost items & Stover & Miscanthus & Switchgrass \\
\hline Fertilizer & 22.7 & 14.0 & 15.6 \\
Transportation & 33.5 & 25.4 & 28.4 \\
Fuel & 3.4 & 4.6 & 5.1 \\
Seed/rhizomes & 0.0 & 6.7 & 1.7 \\
Other costs & 7.0 & 7.5 & 8.0 \\
Labor & 10.0 & 10.7 & 11.5 \\
Land & 0.0 & 2.7 & 5.8 \\
Capital (including profit) & 23.3 & 28.5 & 23.9 \\
\hline Total & 100.0 & 100.0 & 100.0 \\
\hline
\end{tabular}

For details see Taheripour et al. [10].

industry which collects, processes, and transfers corn stover to the biofuel industry. This industry does not need land to provide feedstock and pays fertilizer costs to maintain productivity of land. On the other hand miscanthus and switchgrass use land, as explained later in this section, along with other inputs to produce and deliver feedstock to biofuel industries.

Cellulosic materials produced by the feedstock industries can be converted into either ethanol or biogasoline (a dropin biofuel). The chemical properties and energy content of ethanol produced from cellulosic material are identical to those for corn-based ethanol. However, the chemical properties and energy content of biogasoline differ from ethanol. The chemical properties and energy content of biogasoline are similar to those for conventional gasoline, and the energy content of ethanol is two-thirds that of conventional gasoline. Unlike ethanol for which the US market is mainly limited to E10 (gasoline including 10\% ethanol), biogasoline can be used directly as a substitute for traditional gasoline, and hence its market is not limited. In the advanced biofuel sectors, conversion of cellulosic materials to gasoline-like hydrocarbon fuels follows a thermochemical conversion technology, and conversion of cellulosic materials to ethanol follows a biochemical pathway. These technologies are explained in the National Academy of Science report [8] in detail.

Given that these new industries are not commercially viable, we defined their production technologies based on the available information obtained from the literature and expert inputs. Then these new industries are introduced into the GTAP database. The database modification process is defined based on Taheripour et al. [9] and explained in detail in Taheripour et al. [10]. Tables 1 and 2 represent the cost structures of the new industries.

Table 1 indicates that transportation, fertilizer, and capital are the main cost items in corn stover, miscanthus, and switchgrass industries, which provide feedstock for producing the second generation biofuels included in this model. To provide corn stover no additional land is needed. This industry does not pay for seed or rhizome but pays relatively higher costs to maintain soil nutrients and productivity after removing a portion of corn stover for biofuel production. 
TABLE 2: Cost structures of advanced biofuel producers (percentage of total costs).

\begin{tabular}{|c|c|c|c|c|c|c|}
\hline \multirow{2}{*}{ Cost items } & \multicolumn{3}{|c|}{ Biogasoline } & \multicolumn{3}{|c|}{ Ethanol } \\
\hline & Miscanthus & Switchgrass & Stover & Miscanthus & Switchgrass & Stover \\
\hline Feedstock & 54.6 & 51.9 & 47.7 & 42.9 & 40.2 & 39.2 \\
\hline Chemicals & 0.0 & 0.0 & 0.0 & 15.6 & 16.3 & 18.8 \\
\hline Energy & 1.0 & 1.0 & 1.1 & 4.1 & 4.2 & 4.9 \\
\hline Other costs & 10.5 & 11.1 & 12.1 & 17.5 & 18.3 & 15.0 \\
\hline Labor & 2.2 & 2.4 & 2.6 & 4.4 & 4.6 & 5.3 \\
\hline Capital & 31.8 & 33.7 & 36.6 & 15.6 & 16.3 & 16.9 \\
\hline Total & 100.0 & 100.0 & 100.0 & 100.0 & 100.0 & 100.0 \\
\hline
\end{tabular}

For details see Taheripour et al. [10].

The cost share of transportation is higher in corn stover activity as well. Table 1 also shows that the cost share of land in producing switchgrass is higher than the corresponding figure in producing miscanthus. This is due to the fact that miscanthus yield is higher than switchgrass yield.

Table 2 shows that feedstock is a major cost item in the cost structure of cellulosic biofuel industries. This is a key factor which makes cellulosic biofuels expensive. Table 2 also indicates that the cellulosic biogasoline pathways are more capital intensive than the cellulosic ethanol pathways. On the other hand chemical inputs have a large share in the cost structures of cellulosic ethanol pathways. In developing the cost structure of the new cellulosic industries, it is assumed that they do not produce marketable by-products.

In the database construction process we also used the following important cost items and key assumptions: (i) corn stover, miscanthus, and switchgrass are priced at $\$ 98, \$ 139$, and $\$ 133$ per dry metric ton at 2010 prices, respectively; (ii) given the existing technologies, the production costs of corn stover biogasoline, miscanthus biogasoline, and switchgrass biogasoline are estimated at $\$ 0.82, \$ 0.99$, and $\$ 0.96$ per liter at 2010 prices; (iii) the production costs of producing ethanol form these feedstocks are very close to the production costs of biogasoline, but as mentioned earlier, ethanol has lower energy content compared to biogasoline; (iv) the average annual yields of corn stover, miscanthus, and switchgrass are about $3.4,17.5$, and 10.1 dry metric tons per hectare, respectively, and only up to $33 \%$ of available stover is removed; and (v) the conversion yields for cellulosic biofuels are 250 liters of biogasoline per dry metric ton and 313 liters of ethanol per dry metric ton regardless of feedstock.

Since GTAP database version 7 represents relative prices in 2004, all estimated costs and prices are deflated to their 2004 values using appropriate price deflators. Finally, since biofuels are not produced in the real world yet, it is assumed that the US economy produces small amounts of new biofuels and their corresponding feedstocks in the base year. We also updated the land use and crop data sets of the GTAPBIO database from 2001 to 2004 according to the data sets developed by Avetisyan et al. [11]. Unlike the original GTAPBIO model which assumes that the productivity of new cropland is $2 / 3$ of the existing cropland everywhere across the world, a new set of land conversion factors developed using a terrestrial ecosystem model which measure productivities of new croplands compared to the existing croplands by region and AEZ is used [12].

To handle production and consumption of the new cellulosic biofuels the GTAP-BIO model is also modified. In particular, the biofuels are included in the demand structure of households and the derived demands for firms for energy. In addition, the new industries supply their products to the market and demand intermediate inputs and compete for primary inputs in the markets for labor, land, and capital. In particular, miscanthus and switchgrass compete with other crops in the market for land as shown in Figure 1 which depicts the land supply tree of the earlier versions of the GTAP-BIO model and the new one. The new and old land supply trees are identical in their bottom nest where forestry, livestock, and crop industries compete for available land. However, the cropland nesting structure of the old and new land supply trees are different. Unlike the old model which puts all crops in one nest, the new model puts crop activities into two categories. In one nest, indicated as crop group 1, farmers who produce usual crops (including all types of food, feed, and fiber crops) compete for cropland. The retired US croplands are classified under " $C R P$ ” in this group. In the second nest producers of miscanthus and switchgrass compete with livestock producers for croplandpasture which represent marginal lands which have been cultivated for crop production in the past and currently are used by livestock producers as pasture land. In this nesting structure cropland can move between the groups 1 and 2 . This means that if economic conditions permit, farmers may switch from tradition crops to dedicated energy crops and vice versa. This nesting structure implicitly follows the common ideas that the marginal lands, classified under the cropland-pasture category, are good candidates for producing dedicated crops. While the model covers retired lands under the CRP program, in this paper it is assumed that these lands will not be released for expansion for dedicated energy crops. As mentioned earlier, the original GTAP-BIO model takes into account yield improvement due to higher crop prices. The new model follows this indication for the new dedicated energy crops and cropland-pasture as well. The modifications summarized here are the key modifications, which were introduced into the original GTAP-BIO model to handle second generation biofuels. For a complete list of modifications, see Taheripour et al. [10]. 


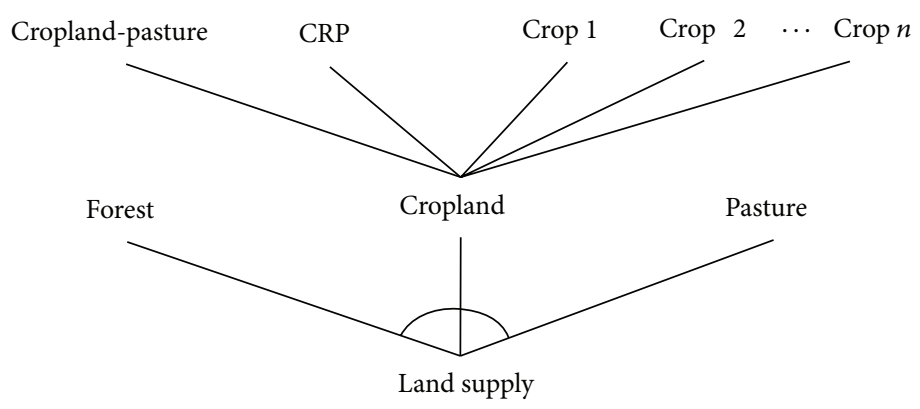

Original land supply tree

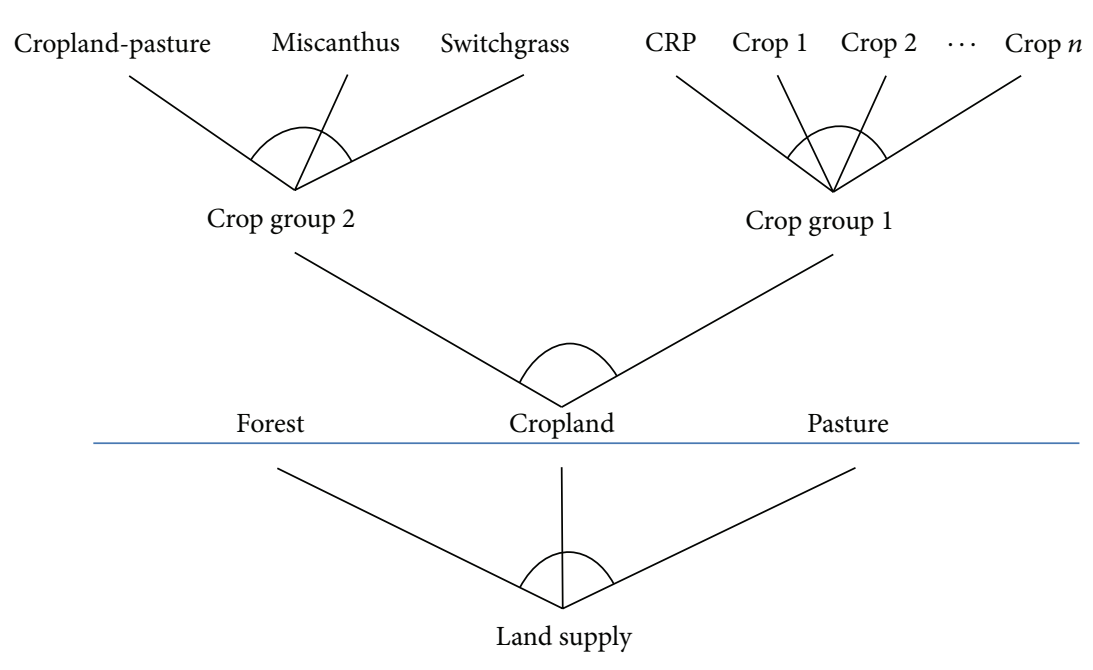

New land supply tree

Figure 1: Land cover and land use activities in the old and new GTAP-BIO-ADV.

2.3. Simulations. To evaluate the ILUCs for alternative biofuel pathways the following experiments were defined:

(a) an increase in corn ethanol production by 43.873 billion liters (BLs.) (from its 2004 level to $56.781 \mathrm{BLs}$, which represents the expected US corn ethanol production for 2015),

(b) an increase in production and consumption of biogasoline produced from corn stover by $22.712 \mathrm{BLs}$, on top of 56.781 BLs corn ethanol,

(c) an increase in production and consumption of biogasoline produced from miscanthus by $17.791 \mathrm{BLs}$, on top of 56.781 BLs corn ethanol,

(d) an increase in production and consumption of biogasoline produced from switchgrass by $17.791 \mathrm{BLs}$, on top of 56.781 BLs corn ethanol,

(e) an increase in production and consumption of ethanol from corn stover by 34.069 BLs, on top of 56.781 BLs corn ethanol,

(f) an increase in production and consumption of ethanol from miscanthus by $26.498 \mathrm{BLs}$, on top of 56.781 BLs corn ethanol, (g) an increase in production and consumption of ethanol from switchgrass by $26.498 \mathrm{BLs}$, on top of 56.781 BLs corn ethanol.

These experiments are defined based on the targets which are included in the US Renewable Fuel Standard (RFS2) for 2015. The RFS2 does not directly mandate corn ethanol. However, since in US ethanol is mainly produced from corn, following the literature we assigned the RFS target for conventional ethanol to corn ethanol. The RFS2 considered about 61 billion liters of advanced biofuel for 2015. However, it does not specify advanced biofuels by feedstock or the geographic origin of biofuel production. In this paper we assumed that advanced biofuel will be produced within the US borders from cellulosic feedstocks, either corn stover or dedicated crops such as miscanthus or switchgrass. To divide the mandated level of advanced biofuel for 2015 between corn stover and dedicated crops we assigned $56 \%$ of the target to corn stover. This target supports a level of corn stover removal which does not go beyond the $33 \%$ rate of corn stover removal mentioned earlier in this paper. Then it is assumed that the rest of the advanced biofuel will be produced from either miscanthus or switchgrass. Finally, the defined targets for advanced ethanol by feedstock are converted to biogasoline equivalents by feedstock according to their 
relative energy contents. The experiment (a) is accomplished using the 2004 database, and other experiments are obtained off of the $56.781 \mathrm{BLs}$ ethanol. This sequence is chosen because the US economy will reach to its goal for corn ethanol soon and prior to producing cellulosic biofuels commercially. Following Hertel et al. [3], in each of these experiments we only shocked the targeted biofuel in that experiment to isolate impacts of biofuel production from other factors which shape the world economy. The ILUCs due to these biofuel pathways are shown in Table 3.

This table shows that the targeted expansion in corn ethanol will expand global cropland by about 2 million hectares $(\mathrm{MH})$ and will shift more than 1.4 MH of US and Brazil cropland-pasture to crop production. Expansion in corn ethanol production leads to conversion of 1.8 million hectares of pasture lands and 0.2 million hectares of deforestation at the global scale. In addition, due to the expansion in corn ethanol the livestock industry loses about 1.4 million hectares of its cropland-pasture in favor of corn production.

Table 3 also shows that producing ethanol or biogasoline from corn stover will generate negligible ILUCs. While producing biofuels from corn stover does not need land, it affects relative land prices in the general equilibrium solution in favor of forestry and marginally causes some reforestation. In this general equilibrium model, the corn stover activity does not change relative profitability of crops at equilibrium. However, in the real world, if corn stover is used for biofuel production we may observe changes in corn-soy rotation in short run [13].

Table 3 shows that producing either ethanol or biogasoline from dedicated crops will induce land use changes as well. However, the patterns of ILUCs due to these biofuels and corn ethanol are very different. Converting corn to ethanol increases the price of corn. This reduces consumption of corn and increases supply of corn. Hence a portion of required feedstock comes from reduction in corn consumption, and a portion comes from expansion in corn production. A portion of required cropland for corn production comes from reduction in production of other crops, and a portion comes from converting forest and pasture to corn production. Hence, in general, expansion in corn ethanol reduces consumption of corn and other crops, and that mitigates required land expansion due to corn ethanol.

The pattern of ILUCs due to an expansion in a dedicated crop-based biofuel is very different. The required feedstock for the desired expansion must be produced, because production is currently about zero. Hence, other land use activates (crops, livestock, and forestry) must give up a portion of their land for producing dedicated crops. Thus the required land for feedstock production should come from the existing croplands, pasture, or forest. When cropland-pasture is used to produce dedicated crops, the price of pasture land, again used by livestock industry, goes up. This changes the relative land prices in favor of pasture land and causes land conversion from forest to pasture land. Table 3 clearly represents this land use change pattern in the US.

Producing biogasoline from miscanthus (case c) generates the lowest land requirement (in terms of new land plus cropland-pasture moved to miscanthus) among alternative
TABLE 3: Land use changes due to biofuel production (1000 hectares) ${ }^{1}$.

\begin{tabular}{lccccc}
\hline Land category & US & EU & Brazil & Others & Total \\
\hline (a) 56.781 billion liters corn ethanol off of 2004 & & \\
Land cover \\
Forest & -331 & -80 & 42 & 144 & -226 \\
Pasture & -639 & -46 & -123 & $-1,043$ & $-1,852$ \\
Cropland & 971 & 126 & 82 & 899 & 2,078 \\
Cropland-pasture $^{2}$ & $-1,169$ & - & -238 & - & $-1,407$ \\
\hline
\end{tabular}

(b) 22.712 billion liters stover biogasoline

Land cover

\begin{tabular}{cccccc} 
Forest & 8 & 2 & 0 & 47 & 56 \\
Pasture & 5 & 0 & 2 & -32 & -24 \\
Cropland & -13 & -2 & -2 & -15 & -32 \\
Cropland-pasture $^{2}$ & 0 & 0 & 6 & - & 6 \\
\hline
\end{tabular}

(c) 17.791 billion liters miscanthus biogasoline

Land cover

$\begin{array}{lccccc}\text { Forest } & -153 & -16 & 8 & 24 & -137 \\ \text { Pasture } & 47 & -9 & -23 & -197 & -183 \\ \text { Cropland } & 106 & 25 & 15 & 173 & 319 \\ \text { pland-pasture }^{2} & -3,719 & - & -43 & - & -3,762\end{array}$

(d) 17.791 billion liters switchgrass biogasoline

Land cover

\begin{tabular}{lccccc} 
Forest & -550 & -45 & 20 & -16 & -590 \\
Pasture & 327 & -20 & -60 & -431 & -185 \\
Cropland & 223 & 65 & 40 & 447 & 775 \\
pland-pasture $^{2}$ & $-6,915$ & - & -113 & - & $-7,028$ \\
\hline
\end{tabular}

(e) 34.069 billion liters stover ethanol

Land cover

\begin{tabular}{cccccc} 
Forest & 19 & 3 & 0 & 52 & 74 \\
Pasture & -6 & 1 & 3 & -28 & -30 \\
Cropland & -13 & -4 & -3 & -25 & -44 \\
Cropland-pasture $^{2}$ & -9 & 0 & 8 & - & -2 \\
\hline
\end{tabular}

(f) 26.498 billion liters miscanthus ethanol

Land cover

\begin{tabular}{lccccc} 
Forest & -221 & -21 & 11 & 26 & -205 \\
Pasture & 88 & -11 & -31 & -249 & -202 \\
Cropland & 134 & 32 & 20 & 222 & 408 \\
ropland-pasture $^{2}$ & $-4,590$ & - & -56 & - & $-4,646$ \\
\hline
\end{tabular}

(g) 26.498 billion liters switchgrass ethanol

Land cover

\begin{tabular}{lccccc} 
Forest & -784 & -61 & 28 & -29 & -845 \\
Pasture & 483 & -28 & -82 & -581 & -208 \\
Cropland & 301 & 89 & 54 & 610 & 1,054 \\
pland-pasture $^{2}$ & $-8,278$ & 0 & -154 & - & $-8,432$ \\
\hline
\end{tabular}

${ }^{1}$ Cases (b) to (g) are in addition to case (a). Positive numbers represent expansion, and negative numbers indicate reduction in each category. ${ }^{2}$ Cropland-pasture is a subcategory under cropland. This row shows conversion of cropland-pasture to other crops.

biofuels produced from dedicated crops. About 3.7 million hectares of land are needed to produce 17.791 billion liters of biogasoline from miscanthus. However, this land requirement is mainly obtained from cropland-pasture. The global 
TABLE 4: Cropland expansion due for selected biofuel pathways.

\begin{tabular}{lcccc}
\hline $\begin{array}{l}\text { Biofuel case which induces } \\
\text { land use changes }\end{array}$ & $\begin{array}{c}\text { Biofuel produced } \\
\text { (billion liters) }\end{array}$ & $\begin{array}{c}\text { New cropland needed } \\
\text { (1000 ha.) }\end{array}$ & $\begin{array}{c}\text { New cropland needed } \\
\text { (ha./1000 liters of biofuel) }\end{array}$ & $\begin{array}{c}\text { New cropland needed } \\
\text { (ha./1000 liters of ethanol equivalent) }\end{array}$ \\
\hline (a) Corn ethanol & 43.873 & 2078 & 0.047 & 0.047 \\
(c) Miscanthus biogasoline & 17.791 & 319 & 0.018 & 0.012 \\
(d) Switchgrass biogasoline & 17.791 & 775 & 0.044 & 0.029 \\
(f) Miscanthus ethanol & 26.498 & 408 & 0.023 & 0.023 \\
(g) Switchgrass ethanol & 26.498 & 1054 & 0.059 & 0.059 \\
\hline
\end{tabular}

cropland expansion for this biofuel pathway is limited to 0.3 million hectares. Converting switchgrass to biogasoline (case d) needs more land because switchgrass yield is lower than miscanthus yield.

As shown in Table 3, in general, producing ethanol from dedicated crops needs more land than producing biogasoline. As mentioned earlier the feedstock conversion rates are about 250 and 313 liters per dry metric ton for biogasoline and ethanol, respectively. But the energy content of ethanol is two-thirds that of biogasoline, which is smaller than the ratio of 250 over 313. Producing 26.498 billion liters ethanol from miscanthus (case g) generates the largest land requirement among all alternative options. It requires about 1 million hectares of new cropland globally, 29\% of which is in the US. Forest constitutes $80 \%$ of the converted land. Globally, 8.5 million hectares of cropland-pasture are needed to support production of 26.498 billion liters of ethanol from switchgrass. The land use impacts of producing biogasoline from switchgrass (case d) and ethanol from miscanthus (case f) fall in between these.

Table 4 summarizes the land needed per $\mathrm{m}^{3}$ of biogasoline or ethanol produced from corn, miscanthus, or switchgrass. Three important conclusions emerge from this table. First, switchgrass needs more land than miscanthus in all cases. This conclusion derives from the assumed lower yield of switchgrass compared with miscanthus. Clearly, dedicated energy crop yield is a key factor in deriving the ILUCs associated with these feedstocks. Second, ethanol requires more land in all cases than biogasoline (in ethanol equivalents) because the conversion efficiency is assumed to be higher for the thermochemical process to produce biogasoline than for the ethanol biochemical process. The results of these experiments provide detailed land use changes among cropland, forest, and pasture and in different global regions by AEZ. For more details on ILUCs see Taheripour et al. [10]. These results are used to calculate ILUC emissions for each biofuel pathway in the next section.

\section{EFs and Their Backgrounds}

In general, research studies in this area have examined three major categories of ILUC emissions released to the atmosphere due to biofuels: (1) $\mathrm{CO}_{2}$ emissions due to changes in vegetative carbon stock; (2) $\mathrm{CO}_{2}$ emissions due to changes in soil carbon stock; (3) and $\mathrm{CO}_{2}$ emissions due to aboveground forgone carbon sequestration. These items tend to capture induced emissions as a result of deforestation due to biofuel expansion. This common classification ignores two important sources of ILUC emissions: non- $\mathrm{CO}_{2}$ emissions due to changes in agricultural practices and changes in soil carbon sequestration due to changes in land cover. Many research studies in this field $[4-6,14,15]$ relied on the vegetation and soil carbon databases developed by the Woods Hole Research Center (WHRC), Winrock International (WI), or Intergovernmental Plan on Climate Change (IPCC) to estimate EFs. These data sets provide highly aggregated regional data on vegetation and soil carbon fluxes. More recently several studies have provided more detailed data on the vegetation and soil carbon fluxes. Zhuang et al. [16] produced a data set on carbon fluxes at the grid cell level using the Terrestrial Ecosystem Model (TEM) at a global scale. This data set can be used to develop land use emission factors at a regional level by Agro Ecological Zone (AEZ). Plevin et al. [17] obtained a data set which measures land use emission factors for several types of vegetation areas divided into 19 regions by AEZ. More recently, the Argonne National Laboratory (ANL) in collaboration with University of Illinois at Chicago have developed a new set of EFs as well [18]. The ANL EFs for non-US regions are based on the Woods Hole data set. However, their EFs for US are constructed using a different approach. Unlike other EFs the ANL EFs for the US take into account changes in soil carbon sequestration due to changes in land cover and tillage practices. This is an important development, because changes in land cover could alter carbon stock in soil. For example, producing miscanthus could improve soil carbon sequestration and increase carbon stock in soil. In its well-to-wheel lifecycle cycle analyses, the ANL now calculates ILUC emissions due to biofuels based on these new EFs in combination with the land use changes obtained from the experiments reported in Table 3 of this paper [19]. These four groups of EFs are analyzed in the next section.

3.1. Woods Hole EFs. This data set divides the world into 10 aggregated regions and provides the following information for each region:

(i) forest area by ecosystem in million hectares,

(ii) carbon in vegetation in metric tons per hectare,

(iii) carbon in soil in metric tons per hectare,

(iv) regrowing forest area in million hectares,

(v) gross carbon uptake by regrowing forests in million metric tons carbon per year,

(vi) carbon uptake by forest area in metric tons carbon per hectare per year. 
Several papers have used this data set in combination with their assumptions on carbon fluxes to obtain regional EFs. For example, Searchinger et al. [14] and Tyner et al. [6] assumed that about $25 \%$ of carbon stored in natural land will be released to the atmosphere when a natural land is converted to cropland. Another common assumption in this area is that a fixed portion of carbon stored in natural vegetation will be released to the atmosphere at the time of land conversion. For example, Tyner et al. [6] assumed that $75 \%$ of carbon stored in the forest type vegetation and $100 \%$ percent of carbon stored in the grassland vegetation will be released into the atmosphere at the time of land conversion. The first three items listed previously are used to calculate reductions in carbon stored in soil and vegetation of natural areas of each region. Furthermore, it is usually assumed that when a natural vegetation area (mainly forest) is converted to cropland, it loses its carbon sequestration capability as long as it is under crop production. The last three items listed previously are usually used to quantify the forgone carbon sequestration $[4,6,14]$. Tyner et al. [6] have explained the Woods Hole data set in detail and used a set of EFs for forest and pasture land based on this data set assuming that the converted natural land to cropland will remain under crop production for 30 years (life time for biofuel production). The EFs developed by these authors are presented in the supplementary materials (see Supplementary Materials available online at http://dx.doi.org/10.1155/2013/315787). These EFs indicate that converting forest to cropland releases significantly larger $\mathrm{CO}_{2}$ emissions compared to pasture land.

3.2. California Air Resources Board (CARB) EFs. An expert working group at $\mathrm{CARB}$ concluded that improvements were needed in the Woods Hole data [20]. To reduce EF uncertainties and eliminate inherent deficiencies in EFs obtained from Woods Hole data, the CARB has developed a new data set and a program which provide EFs for 18 Agro Ecological Zones (AEZ) in each region at a global scale [9]. The new CARB data set divides the world into 19 regions presented in GTAP$\mathrm{BIO}$ model and includes the following sinks and sources of GHG emissions from LUC:

(i) aboveground live biomass (trunks, branches, and foliage),

(ii) belowground live biomass (coarse and fine roots),

(iii) dead organic matter (dead wood and litter),

(iv) soil organic matter,

(v) harvested wood products,

(vi) Non- $\mathrm{CO}_{2}$ climate-active emissions (e.g., $\mathrm{CH}_{4}$ and $\mathrm{N}_{2} \mathrm{O}$ ),

(vii) forgone sequestration.

These data items are collected from the existing databases and literature, and then in combination with a series of detailed assumptions on carbon fluxes, the CARB new EFs are calculated for the following main categories of land conversions: (i) forest to cropland and reverse, (ii) pasture to cropland and reverse, (iii) cropland-pasture to cropland and reverse, (iv) and pasture to forest and reverse. Unlike the EFs developed based on Woods Hole data, the CARB EFs for converting one type of land to another type and their reverse are not identical. For example, the EFs for converting forest to cropland and returning croplands to forest are not identical for the same region, AEZ. The CARB EFs are available in several tables of the supplementary materials. These tables indicate that the EFs vary significantly across regions and AEZs. In addition they show that EFs of forest to cropland $>$ EFs of forest to pasture land $>$ EFs of pasture land to cropland $>$ EFs of cropland-pasture to cropland. The CARB EFs included here are not yet official CARB factors.

As described in Plevin et al. [17] and Yeh et al. [20] the carbon pools used in developing the new CARB EFs factors are taken from several databases which represent different biophysical modeling frameworks. Since each of these models operates based on a wide range of assumptions, it is not an easy task to check the assumptions behind each model and the consistency of the assumptions among biophysical models.

3.3. TEM EFs. The EFs which are developed to date have three main components: carbon stock in soil, carbon stock in vegetation, and forgone carbon sequestration. Zhuang et al. [16] have generated a data set which provides data on soil and vegetation carbon pools and Net Primary Production (NPP) at an $0.5^{\circ} \times 0.5^{\circ}$ (latitude by longitude) spatial resolution. The TEM model, a process-based biogeochemistry model, is used to develop this data set. These authors have developed illustrative EFs for the US economy at AEZ level based on the outputs of the TEM model. This section follows the approach provided by these authors and develops a set of regional EFs at the AEZ level using the outputs of the TEM model in combination with assumptions on carbon fluxes. To establish a base case, a set of TEM EFs was developed with the common assumptions which have been used earlier in several research studies. The base case assumptions are as follows:

(a) at the time of land conversion (either from forest of pasture land to cropland) $25 \%$ of carbon stored in soils will be released to the atmosphere;

(b) at the time of land conversion $75 \%$ of carbon stored in forest vegetation (above- and underground) will be released to the atmosphere;

(c) at the time of land conversion $100 \%$ of carbon stored in pasture land vegetation (above- and underground) will be released to the atmosphere;

(d) forgone forest carbon sequestration is equal to $25 \%$ of annual NPP;

(e) no forgone carbon sequestration for pasture land and cropland-pasture;

(f) EFs for converting cropland-pasture to cropland are $50 \%$ of those for converting pasture land to cropland.

The TEM EFs under these base case assumptions are available in the supplementary materials. Comparing these EFs with their CARB corresponding EFs indicates that in many cases, in particular for forest EFs, these two sources represent relatively similar EFs. However, major differences 
TABLE 5: Estimated induced land use emissions due to biofuel production for alternative land use emission factors $\left(\mathrm{g} \mathrm{CO}_{2} \mathrm{e} \mathrm{MJ}^{-1}\right)$.

\begin{tabular}{lccccccr}
\hline Case & \multirow{2}{*}{ Feedstock } & Biofuel & Without CP-EF & & \multicolumn{2}{c}{ With CP-EF $^{2}$} \\
& & & WH $^{3}$ & CARB $^{4}$ & TEM $^{5}$ & WH $^{3}$ & CARB $^{4}$ \\
\hline (a) & Corn & Ethanol & 12.9 & 15.1 & 17.0 & 15.5 & 18 \\
(b) & Corn stover & Biogasoline & -1.0 & -1 & -1.1 & -1.0 & -1 \\
(c) & Miscanthus & Biogasoline & 6.1 & 7.1 & 7.3 & 18.1 & 19.4 \\
(d) & Switchgrass & Biogasoline & 21.4 & 24.9 & 23.4 & 43.7 & 47.6 \\
(e) & Corn stover & Ethanol & -1.0 & -1.4 & -1.5 & -0.9 & -1.4 \\
(f) & Miscanthus & Ethanol & 5.8 & 10.1 & 10.1 & 15.7 & 25.6 \\
(g) & Switchgrass & Ethanol & 20.3 & 35.5 & 33.1 & 38.2 & -1.6 \\
\hline
\end{tabular}

${ }^{1}$ It is assumed that converting cropland-pasture to cropland (either for producing traditional crop or dedicated energy crops) does not cause land use emissions. ${ }^{2}$ It is assumed that converting cropland-pasture to cropland (either for producing traditional crop or dedicated energy crops) causes land use emissions. ${ }^{3}$ Based on EFs obtained from the Woods Hole data set. ${ }^{4}$ Based on CARB EFs. ${ }^{5}$ Based on the TEM EFs obtained for the base case assumption.

can be observed, in particular, among pastureland EFs. Two factors can explain differences between TEM and CARB EFs. First, these EFs could be different because they use different carbon pools. Second, CARB uses more detailed regional assumptions on carbon fluxes compared to the simple assumptions used for the TEM case.

3.4. ANL EFs. In developing WH, CARB, and TEM EFs it is assumed that a portion of soil carbon stock will be released to the atmosphere at the time deforestation due to biofuels occurs. However, the fact that soil carbon sequestration capability can also change due to changes in vegetation cover is ignored in this area. Several papers have shown that converting cropland or grassland to production of dedicated energy crops such as miscanthus and switchgrass can increase soil carbon content (e.g., see Anderson-Teixeira et al. [21]). Taking this factor into account could significantly affect the magnitude of estimates of ILUC emissions due to biofuels, in particular for cellulosic materials. The ANL has taken into account this important factor in developing its EFs.

The ANL EFs for non-US regions are identical to WH EFs factors. However, to develop the US EFs a different approach is followed. To develop EFs factor for US, two distinct carbon sources of below- and aboveground are recognized. To assess changes in belowground carbon stocks the CENTRURY model originally developed at Colorado State University is used [22]. This model calculates changes in soil carbon sequestration when land cover is changing from one type to another. The model distinguishes three primary soil organic matter pools (active, slow, and passive) and traces impacts of changes in land cover and land management practice on these pools. The EFs for below ground carbon stock are provided at the state level [18]. Evaluating impacts of changes in land cover vegetation on soil carbon sequestration is an important component of the ANL EFs which is missing in other EFs mentioned in this paper. This is of particular importance for producing dedicated crops which could improve soil carbon sequestration.

To evaluate changes in above ground carbon stock the Carbon Online Estimator (COLE) databases developed by USDA is used [23]. This database provide information for five types of nonsoil carbon stocks including aboveground live tree carbon density, aboveground dead tree carbon density, understory carbon density, forest floor carbon density, and coarse woody debris carbon density by state. This data set also is used to assess the above ground forgone carbon sequestration due to biofuel production. The ANL has developed several sets of EFs for US by state for different land management practices, alternative assumptions on soil decay factor and soil erosion in the presence and absence of crop yield improvement. The Carbon Calculator for Land Use Change from Biofuels Production (CCLUB) developed by ANL presents these EFs [18].

\section{ILUC Emissions and Sensitivity Tests}

In this section we first calculate ILUC emissions for the biofuel pathways presented in Table 3 in combination with the EFs obtained based on Woods Hole, CARB, and TEM databases which ignore impacts of changes in soil carbon sequestration due to changes in land cover vegetation. Then we test the sensitivity of results obtained from the TEM EFs with respect to changes in the base assumptions used in derivation of these EFs. Finally, we calculate ILUC emissions for alternative ethanol pathways presented in Table 3 in combination with several sets of EFs developed by ANL. This will help us to assess changes in ILUC emissions when we take into account changes in soil carbon sequestration due to changes in land cover vegetation.

First consider Table 5 which represents the results obtained from the first three groups of EFs and starts with the cases where we assume that converting cropland-pasture to cropland (either for producing traditional crops or dedicated energy crops) has no land use emissions (see the first three numerical columns of Table 5).

The results indicate that the estimated ILUC emissions vary across alternative sets of EFs and biofuels. In general, regardless of biofuel type, the Woods Hole EFs generate the lowest land use emissions, and the TEM EFs predict the highest emissions. The estimated emissions obtained from the CARB and TEM EFs generally are not very different. Among alternative biofuels, corn stover ethanol and corn stover biogasoline do not have land use emissions because there is little land use change. However, any change in soil 
TABle 6: Percentage changes in estimated land use emissions obtained from CARB or TEM compared to Woods Hole (\%).

\begin{tabular}{llcccccc}
\hline \multirow{2}{*}{ Case } & \multirow{2}{*}{ Feedstock } & \multirow{2}{*}{ Biofuel } & WH & Without CP-EF & \multicolumn{3}{c}{ With CP-EF } \\
& & & CARB & TEM & WH & CARB & TEM \\
\hline (a) & Corn & Ethanol & 0.0 & 17.1 & 31.8 & 0.0 & 16.1 \\
(c) & Miscanthus & Biogasoline & 0.0 & 16.4 & 19.7 & 0.0 & 75.8 \\
(d) & Switchgrass & Biogasoline & 0.0 & 16.4 & 9.3 & 0.0 & 8.9 \\
(f) & Miscanthus & Ethanol & 0.0 & 74.1 & 74.1 & 0.0 & 61.8 \\
(g) & Switchgrass & Ethanol & 0.0 & 74.9 & 63.1 & 0.0 & 64.9 \\
\hline
\end{tabular}

carbon due to residue removal has not been considered. Miscanthus biogasoline and switchgrass ethanol have the lowest and highest land use emissions, respectively. For example, with the CARB EFs these fuels cause about $7.1 \mathrm{~g} \mathrm{CO}_{2} \mathrm{e} \mathrm{MJ}^{-1}$ and $35.5 \mathrm{~g} \mathrm{CO}_{2} \mathrm{e} \mathrm{MJ}^{-1}$ emissions. The estimated emissions for corn ethanol are about $15.1 \mathrm{~g} \mathrm{CO}_{2} \mathrm{e} \mathrm{MJ}^{-1}$. Finally, the ethanol pathway consistently has higher land use changes and higher emissions than the thermochemical pathway. The emissions increase is substantially higher for the CARB and TEM emission factors because of the large proportion of the increase that comes from forestry, and because the CARB and TEM factors are more detailed and better able to associate the land use changes in the actual AEZ/region from GTAP.

We now present changes in ILUC emissions if we assume converting cropland-pasture to cropland causes land use emissions. Indeed, in this test we adopt the CARB logic which assumes that the EF for converting cropland-pasture to cropland is about $50 \%$ of the $\mathrm{EF}$ of converting pasture land to cropland. Adopting this assumption increases the estimates for ILUC emissions for biofuels produced from corn, miscanthus, and switchgrass significantly (see the last three columns of Table 5 and Figure 2). In particular, emissions due to fuels produced from dedicated crops escalate largely due to adopting this assumption. For example, with the CARB EFs the estimated emissions for miscanthus biogasoline and switchgrass ethanol increase from $7.1 \mathrm{~g} \mathrm{CO}_{2} \mathrm{e} \mathrm{MJ}^{-1}$ and $35.5 \mathrm{~g} \mathrm{CO}_{2} \mathrm{e} \mathrm{MJ}^{-1}$ to $19.4 \mathrm{CO}_{2} \mathrm{e} \mathrm{MJ}$ and $63 \mathrm{CO}_{2} \mathrm{e} \mathrm{MJ}^{-1}$, respectively. The rate for corn ethanol goes up moderately from $15.1 \mathrm{~g} \mathrm{CO}_{2} \mathrm{e} \mathrm{MJ}^{-1}$ to $18 \mathrm{~g} \mathrm{CO}_{2} \mathrm{e} \mathrm{MJ}^{-1}$.

Adopting this assumption also increases the gap between the estimated emissions obtained from different sources of EFs. Table 6 illustrates percentage changes in estimated emissions obtained from the CARB and TEM EFs compared with their WH corresponding figures for the cases with and without cropland-pasture. This table shows that corn ethanol emissions increase 32\% using TEM and $46 \%$ if croplandpasture is included. CARB increases are about half those levels. Biogasoline has the smallest differences among the three EFs. Miscanthus is $20 \%$ higher with TEM and $16 \%$ with CARB, while switchgrass is $9 \%$ higher with TEM and $16 \%$ with CARB. Inclusion of cropland-pasture substantially increases the emissions-by $41 \%$ for miscanthus and $30 \%$ for switchgrass. The biggest variation is for ethanol for the same reasons as in the previous case. Without croplandpasture, emissions increase $74 \%$ and $63 \%$ for miscanthus and switchgrass for TEM with somewhat similar levels for CARB. With cropland-pasture, the miscanthus increase is $106 \%$ for
With cropland-pasture emissions
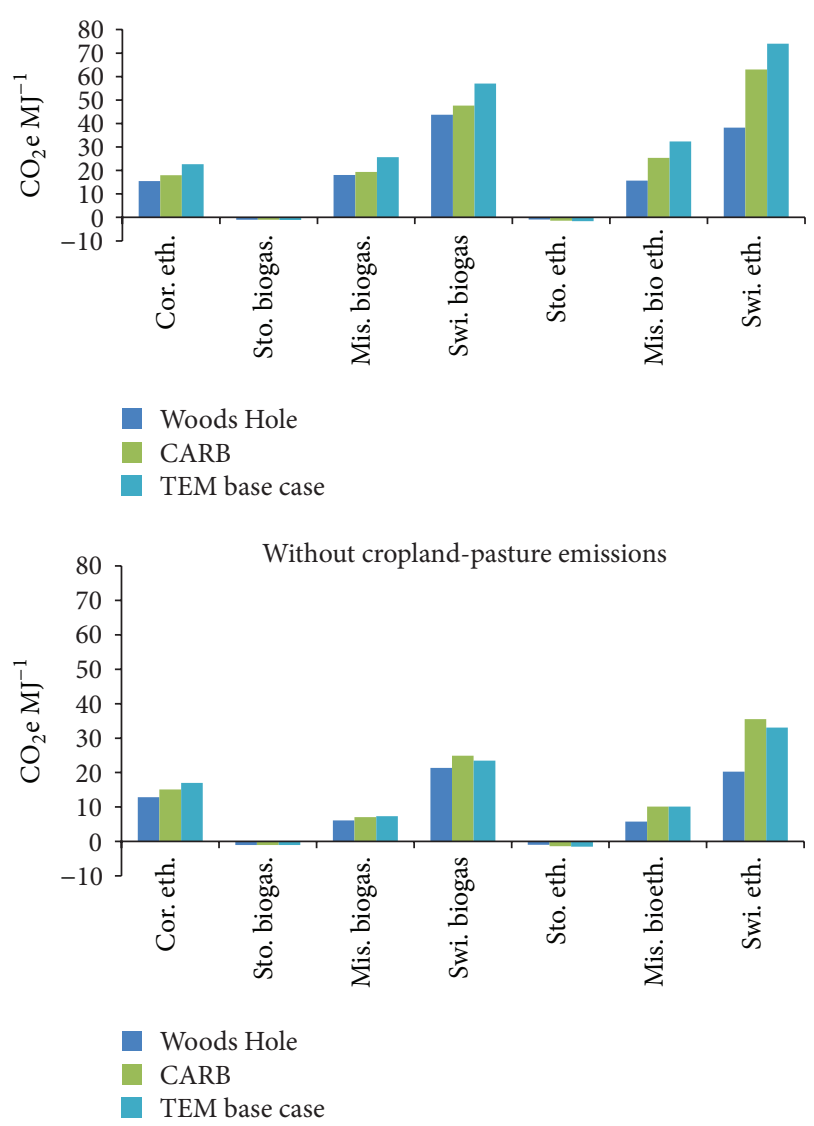

Figure 2: Induced land use emissions with and without croplandpasture emissions.

miscanthus and $94 \%$ for TEM. For CARB, the increases are $62 \%$ and $65 \%$, respectively. Again, this is because much of the land use change for cropland-pasture is in AEZs with higher emission factors.

These results lead us to two important deficiencies in this area. A common assumption is that converting croplandpasture to cropland has zero land use emission. The previous comparison shows that the ad hoc assumption of croplandpasture having $50 \%$ of the emissions of pasture conversion significantly changes the results, in particular for the second generation biofuels produced from dedicated crops, which are assumed to be grown on marginal land such as croplandpasture. Adequate and reliable data is needed to develop EFs for cropland-pasture areas. 
TABLE 7: Sensitivity of TEM estimated induced land use emissions with respect to changes in assumed rates of carbon fluxes for selected biofuel pathways.

\begin{tabular}{lcccccc}
\hline \multirow{2}{*}{ Biofuel pathway } & \multicolumn{3}{c}{ ILUC emissions in $\mathrm{g} \mathrm{CO}_{2} \mathrm{e} \mathrm{MJ}^{-1}$} & \multicolumn{3}{c}{ Percent changes compared to base case } \\
& Base case & Test 1 & Test 2 & Base case & Test 1 & Test 2 \\
\hline (a) & 15.1 & 13.7 & 19.4 & 0.0 & -9.3 & 28.5 \\
(c) & 7.1 & 5.8 & 8.7 & 0.0 & -18.3 & 22.5 \\
(d) & 24.9 & 18.2 & 28.4 & 0.0 & -26.9 & 14.1 \\
(f) & 10.1 & 8.0 & 12.1 & 0.0 & -20.8 & 19.8 \\
(g) & 35.5 & 25.7 & 40.1 & 0.0 & -27.6 & 13.0 \\
\hline
\end{tabular}

It is important to note that Table 4 shows that the CARB and TEM emission estimates are consistently larger than those for the $\mathrm{WH}$, regardless of whether cropland-pasture EFs are considered. This is due to the fact that the $\mathrm{WH}$ database provides lower estimates for soil and vegetation carbon pools. For example, the WH EF for converting forest to cropland for US is about $19.6 \mathrm{Mg} \mathrm{CO}_{2} \mathrm{ha}^{-1} \mathrm{y}^{-1}$, while the CARB forest EFs for US by AEZ range from 15.6 to 43.3 with a weighted average of $22.4 \mathrm{Mg} \mathrm{CO}_{2} \mathrm{ha}^{-1} \mathrm{y}^{-1}$. This difference can be observed in other regions and for pasture land as well. Comparing the WH EF with TEM EFs factors provides the same conclusion.

We now examine sensitivity of estimated ILUC emissions with respect to changes in the common assumptions on carbon fluxes which are used in developing all types of EFs. For this test we stay with the assumption that croplandpasture conversion does not cause land use emissions. We observed that under this assumption the CARB and TEM emission factors lead to somewhat similar estimates for ILUC emissions for every biofuel examined in this paper. Given this fact and given that the assumptions behind the CARB emission factors are very detailed, in this test we only examine the sensitivity of results with respect to changes in the base case assumptions used in construction of the TEM EFs. For this purpose we defined the following tests.

Test 1

(i) Reduction in rate of soil carbon release from $25 \%$ to $15 \%$.

(ii) Reduction in rate of vegetation carbon release from $75 \%$ to $65 \%$ for forest areas and $100 \%$ to $90 \%$ for pasture areas.

(iii) Reduction in rate of forgone sequestration from $25 \%$ to $15 \%$.

Test 2

(i) Increase in rate of soil carbon release from $25 \%$ to $35 \%$.

(ii) Increase in rate of vegetation carbon release from $75 \%$ to $85 \%$ for forest area and no changes for pasture area.

(iii) Increase in rate of forgone sequestration from $25 \%$ to $35 \%$.
TABLE 8: Induced land use emissions for ethanol pathways by feedstock calculated with ANL and Woods Hole emissions factors $\left(\mathrm{g} \mathrm{CO}_{2} \mathrm{e} \mathrm{MJ}^{-1}\right.$ ).

\begin{tabular}{lcccc}
\hline Description & Corn & Stover & Miscanthus & Switchgrass \\
\hline $\begin{array}{l}\text { Minimum } \\
\text { emissions with }\end{array}$ & 3.4 & -1.3 & -12.3 & 1.3 \\
$\begin{array}{l}\text { ANL EFs } \\
\text { Maximum }\end{array}$ & & & & \\
emissions with & 12.3 & -1.2 & -3.5 & 16.4 \\
$\begin{array}{l}\text { ANL EFs } \\
\text { Emissions with }\end{array}$ & & & & \\
$\begin{array}{l}\text { WH without } \\
\text { CP-EF }\end{array}$ & 12.9 & -1 & 5.8 & 20.3 \\
$\begin{array}{l}\text { Emissions with } \\
\text { WH with }\end{array}$ & 15.5 & 0.9 & 15.7 & 38.2 \\
CP-EF & & & & \\
\hline
\end{tabular}

The ILUC emissions are calculated for each of these two tests in combination with ILUCs reported in Table 3 for all biofuels except for corn stover biofuels which do not generate ILUC emissions. The results are presented in Table 7. For test one, the reduction in emissions ranged between $-9 \%$ and $-28 \%$. For test two, the increases in emissions ranged between $13 \%$ and $29 \%$. These figures confirm that the estimated ILUC emissions are sensitive to changes in our assumptions on the rates for carbon fluxes.

We now use the ANL EFs to examine impacts of changes in soil carbon sequestration due to changes in land cover vegetation. As mentioned earlier ANL developed several sets of EFs for different calibration processes used to tune the CENTURY model and under alternative assumptions on land management practices, soil decay factor, soil erosion, and yield improvement. Here we present the highest and lowest calculated ILUC emissions for all possible assumptions defined by ANL for the ethanol pathways introduced and analyzed in this paper. Table 8 represents the results and compares them with the calculated emissions using the $\mathrm{WH}$ EFs. Figures presented in this table clearly show that the range of estimated ILUC emissions with ANL EFs for each ethanol pathway is very wide. For example, the range for corn ethanol is from $3.4 \mathrm{~g} \mathrm{CO}_{2} \mathrm{e} \mathrm{MJ} J^{-1}$ to $12.3 \mathrm{~g} \mathrm{CO}_{2} \mathrm{e} \mathrm{MJ}^{-1}$. This table also indicates that the upper bounds of emissions obtained from the ANL EFs are smaller than the emissions obtained from the WH EFs without CP-EF for all ethanol pathways. The differences for ethanol produced from miscanthus and 
switchgrass are quite large. This is mainly because the ANL EFs take into account changes in soil carbon sequestration due to changes in land cover vegetation. In every case, the ANL emission factors result in lower biofuel emissions due to ILUC than WH, and WH is less than TEM or CARB.

\section{Conclusions}

Estimated biofuel ILUC emissions are uncertain not only because their associated land use changes are uncertain, but also because of uncertainty in the land use EFs. This paper highlights uncertainties in EFs. To accomplish this task first we obtained ILUCs for several biofuel pathways using an improved version of the GTAP-BIO model which handle production and consumption of the first and second generation biofuels. The result for corn stover is in line with the most recent estimates for this biofuel. The results for the second generation biofuels show that expansions in cellulosic biofuels produced from dedicated crops will mainly shift existing cropland-pasture (which represents marginal) to production of dedicated crops. Producing dedicated crops also causes moderate deforestation. We showed that converting corn stover to biofuel barely affects land use. Among cellulosic biofuels, producing ethanol from switchgrass generates more land use changes. The results for ILUCs provided in this paper are subject to uncertainty. However, these base values were then combined with four sets of emission factors to highlight the uncertainties associated with emission factors. We showed that the Woods Hole, CARB, TEM, and ANL EFs are different because their sources on carbon pools are different. In general, the Woods Hole EFs are smaller than the CARB and TEM EFs. The CARB and TEM forest emission factors are close in many cases, but major differences are observed as well. The pasture land EFs of these two sources are significantly different in many cases. In general, the TEM EFs for pasture land are larger than their CARB corresponding figures. We showed that including changes in soil carbon sequestration due to changes in land cover vegetation affect the EFs significantly.

We examined the CARB assumption that converting cropland-pasture to cropland generates land use emissions and that the EFs for this type of land conversion are about $50 \%$ of EFs of pasture land. We observed that adopting this assumption increases the estimated ILUC emissions obtained from all types of EFs for biofuel pathways which induce LUCs, in particular for the second generation of biofuels, which mainly use dedicated crops produced on cropland-pasture areas in the US. Finally we observed that the results are very sensitive to the changes in the common assumptions about the rates of carbon fluxes. We also showed that the ANL EFs which take into account changes in soil carbon sequestration are very sensitive to the assumptions such as soil decay, soil erosion, land management, and yield improvement. However, the ANL factors were uniformly lower than any of the other factors considered in this analysis.

The three major conclusions from this emissions analysis are (1) inclusion or exclusion of cropland-pasture makes a huge difference; (2) changes in soil carbon sequestration due to changes in land cover vegetation plays an important role; and (3) there is wide divergence among the emission factor sources, especially for dedicated crop conversion to ethanol.

\section{Acknowledgments}

The authors acknowledge financial support for this research from the US Department of Agriculture, National Institute for Food and Agriculture (NIFA).

\section{References}

[1] B. Wicke, P. Verweij, H. Meijl, D. Vuuren, and A. Faaij, "Indirect land use changes: review of existing models and strategies for mitigation," Biofuels, vol. 3, no. 1, pp. 87-100, 2012.

[2] F. Taheripour, T. Hertel, W. Tyner, J. Beckman, and D. Birur, "Biofuels and their by-products: global economic and environmental implications," Biomass and Bioenergy, vol. 34, no. 3, pp. 278-289, 2010.

[3] T. Hertel, W. Tyner, and D. Birur, "The global impacts of biofuel mandates," The Energy Journal, no. 1, pp. 75-100, 312010.

[4] T. W. Hertel, A. A. Golub, A. D. Jones, M. O’Hare, R. J. Plevin, and D. M. Kammen, "Effects of US Maize ethanol on global land use and greenhouse gas emissions: estimating market-mediated responses," BioScience, vol. 60, no. 3, pp. 223-231, 2010.

[5] F. Taheripour, T. W. Hertel, and W. E. Tyner, "Implications of biofuels mandates for the global livestock industry: a computable general equilibrium analysis," Agricultural Economics, vol. 42, no. 3, pp. 325-342, 2011.

[6] W. Tyner, F. Taheripour, Q. Zhuang, D. Birur, and U. Baldos, Land Use Changes and Consequent $\mathrm{CO}_{2}$ Emissions due to US Corn Ethanol Production: A Comprehensive Analysis, Argonne National Laboratory, Chicago, Ill, USA, 2010.

[7] A. Golub and T. Hertel, "Modeling land-use change impacts of biofuels in the GTAP-BIO framework," Climate Change Economics, vol. 3, no. 3, 2012.

[8] National Academy of Sciences, National Academy of Engineering, and National Research Council, Liquid Transportation Fuels from Coal and Biomass: Technological Status, Costs, and Environmental Impacts, National Academies Press, 2009.

[9] F. Taheripour, D. Birur, T. Hertel, and W. Tyner, Introducing Liquid Biofuel into the GTAP Database, GTAP Research Memorandum no. 11, Center for Global Trade Analysis, Purdue University, West Lafayette, Ind, USA, 2007.

[10] F. Taheripour, W. Tyner, and M. Wang, Global Land Use Changes due to the U.S. Cellulosic Biofuel Program Simulated with the GTAP Model, Argonne National Laboratory, Chicago, Ill, USA, 2011.

[11] M. Avetisyan, U. Baldos, and T. Hertel, Development of the GTAP Version 7 Land Use Data Base in GTAP, Research Memorandum no. 19, Purdue University, West Lafayette, Ind, USA, 2010.

[12] F. Taheripour, Z. Qianlai, W. Tyner, and X. Lu, "Biofuels, cropland expansion, and the extensive margin," Applied Science, vol. 3, pp. 14-38, 2012.

[13] J. Fiegel, Development of viable corn stover market: impacts on corn and soybean markets [M.S. thesis of Science], Purdue University, 2012.

[14] T. Searchinger, R. Heimlich, R. A. Houghton et al., "Use of U.S. croplands for biofuels increases greenhouse gases through 
emissions from land-use change," Science, vol. 319, no. 5867, pp. 1238-1240, 2008.

[15] P. Al-Riffai, B. Dimaranan, and D. Laborde, Global Trade and Environmental Impact Study of the EU Biofuels Mandate, International Food Policy Research Institute, Washington, DC, USA, 2010.

[16] Q. Zhuang, F. Taheripour, W. Tyner, and T. Hertel, "Estimating changes of global vegetation and soil carbon storage due to biofuel production," in Proceedings of the 12th Annual Conference on Global Economic Analysis, Santiago, Chile, June 2009.

[17] R. Plevin, H. Gibbs, J. Duffy, S. Yui, and S. Yeh, Agro-Ecological Zone Emission Factor Model, California Air Resources Board, Sacramento, Calif, USA, 2011.

[18] S. Mueller, J. Dunn, and M. Wang, Carbon Calculator for Land Use Change from Biofuels Production: Users' Manual and Technical Documentation, Energy Systems Division, Argonne National Laboratory, Chicago, Ill, USA, 2012.

[19] M. Wang, J. Han, J. B. Dunn, H. Cai, and A. Elgowainy, "Wellto-wheels energy use and greenhouse gas emissions of ethanol from corn, sugarcane and cellulosic biomass for US use," Environmental Research Letter 7, 2012.

[20] S. Yeh, H. Gibbs, S. Mueller, R. Nelson, and D. O'Connor, Low Carbon Fuel Standard (LCFS) Indirect Land Use Change Expert Workgroup: A Report to the California Air Resources Board, California Air Resources Board, Sacramento, Calif, USA, 2010.

[21] K. Anderson-Teixeira, S. Davis, M. Masters, and E. Delucia, "Changes in soil organic carbon under biofuel crops," $G C B$ Bioenergy, vol. 1, no. 1, pp. 75-96, 2009.

[22] H. Y. Kwon and R. J. M. Hudson, "Quantifying managementdriven changes in organic matter turnover in an agricultural soil: an inverse modeling approach using historical data and a surrogate CENTURY-type model," Soil Biology and Biochemistry, vol. 42, no. 12, pp. 2241-2253, 2010.

[23] P. C. van Deusen and L. S. Heath, "Weighted analysis methods for mapped plot forest inventory data: tables, regressions, maps and graphs," Forest Ecology and Management, vol. 260, no. 9, pp. 1607-1612, 2010. 

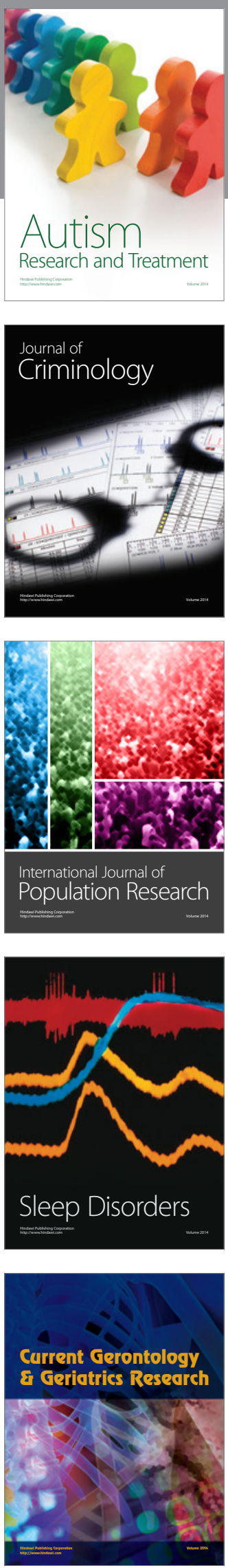
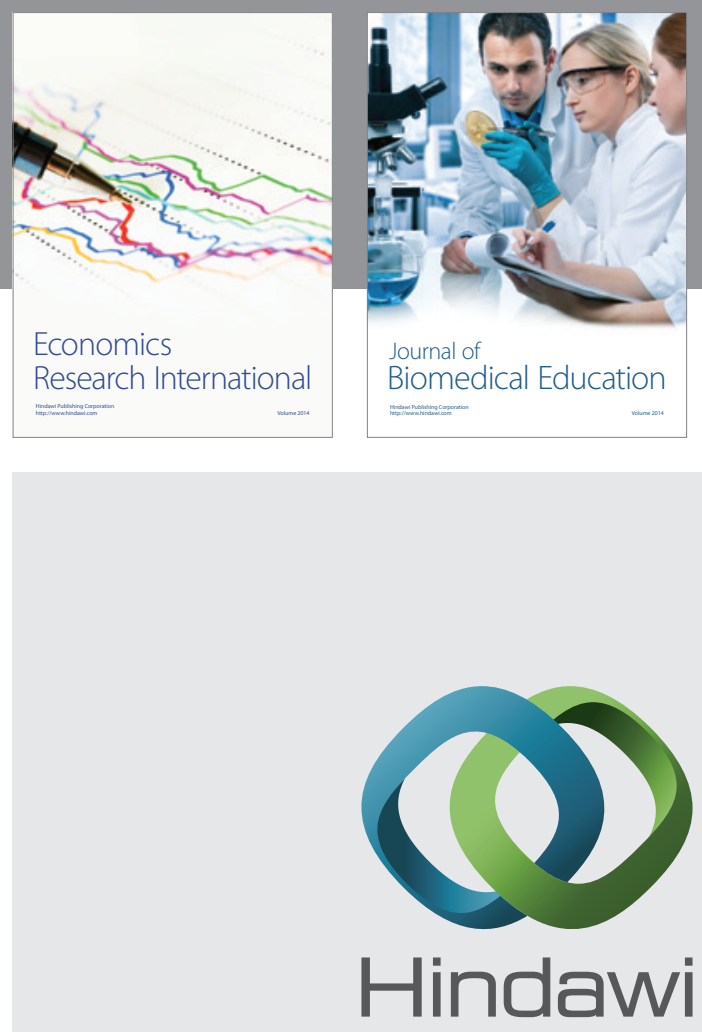

Submit your manuscripts at

http://www.hindawi.com

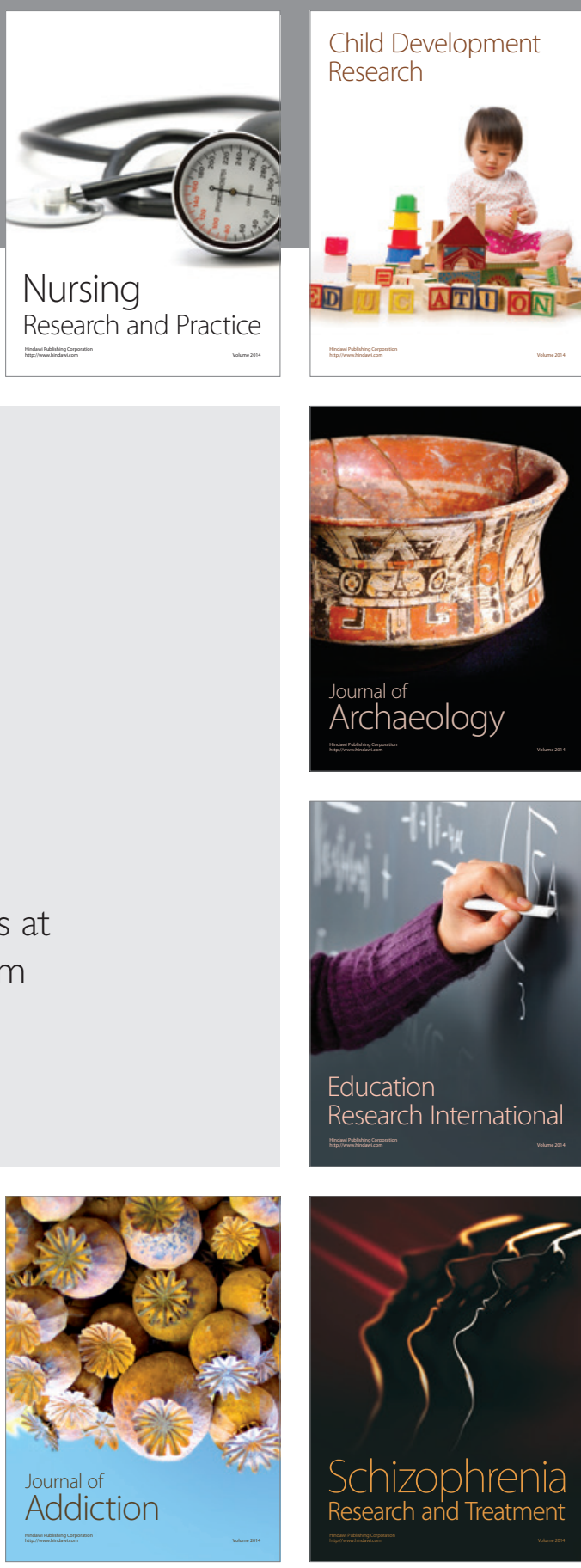

(D)
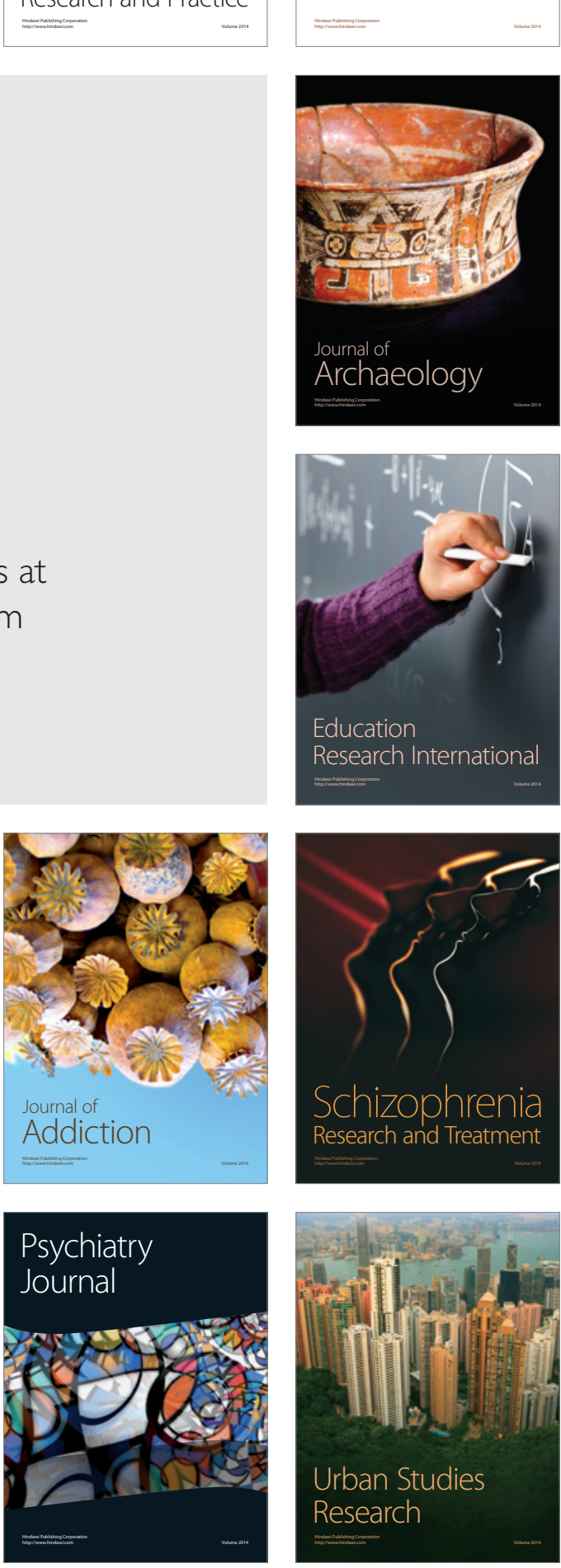